\section{Psicologia Escolar \\ e Educacional}

ARTIGO

DOI: http://dx.doi.org/10.1590/2175-35392021229866

Localizador - e229866

\title{
PROXÊMICA E COMUNICAÇÃO NÃO VERBAL NA INTERAÇÃO EM SALA DE AULA
}

\author{
Danyal Farsani ${ }^{1} \mathbb{D}$; Jackeline Rodrigues ${ }^{2} \mathbb{D}$
}

RESUMO

Este artigo relata um estudo realizado sobre a interação professor-aluno em uma escola pública dos anos iniciais, na cidade de Santiago, Chile. O estudo realizou uma análise quantitativa dos quadros das imagens capturadas por uma minicâmera montada em óculos de um grupo de 18 estudantes. Os quadros selecionados foram os que a professora aparece no campo visual dos alunos. A análise foi desenvolvida a partir do conceito de proxêmica e os resultados mostram que há momentos em que a professora da sala de aula interage com os alunos em um nível mais próximo e, em outros, há um distanciamento maior. Além disso, foi possível identificar diferenças entre meninos e meninas quanto aos padrões proxêmicos de envolvimento visual na interação. Os resultados deste estudo sinalizam novos sentidos para a análise da interação professor-aluno com foco em aspectos não verbais na construção das relações de ensino e aprendizagem.

Palavras-chave: interação professor-estudante; proxêmica; comunicação não-verbal

\section{Proxemic and nonverbal communication in clasroom interaction}

\begin{abstract}
This article reports a study carried out about teacher-student interaction in a public school in the early years, in the city of Santiago, Chile. The study performed a quantitative analysis of the frames of images captured by a mini camera mounted on eyeglasses of a group of 18 students. The selected frames were those that the teacher appears in the students' visual field. The analysis was developed from the concept of proxemics and the results show that there are times when the classroom teacher interacts with students at a closer level and, in others, there is a greater distance. Furthermore, it was possible to identify differences between boys and girls regarding the proxemic patterns of visual involvement in the interaction. The results of this study indicate new directions for the analysis of teacher-student interaction, focusing on non-verbal aspects in the construction of teaching and learning relationships.
\end{abstract}

Keywords: teacher student interaction; proxemics; nonverbal communication

\section{Proxémica y comunicación no verbal en la interacción en sala de clase}

\section{RESUMEN}

En este artículo se relata un estudio realizado sobre la interacción profesor-alumno en una escuela pública de los años iniciales, en la ciudad de Santiago, Chile. En el estudio se realizó un análisis cuantitativo de los cuadros de las imágenes capturadas por una minicámara montada en gafas de un grupo de 18 estudiantes. Los cuadros seleccionados fueron los que la profesora aparece en el campo visual de los alumnos. El análisis se desarrolló a partir del concepto de proxémica y los resultados apuntan que hay momentos en que la profesora de la sala de clase interactúa con los alumnos en un nivel más cercano, en otros, hay un alejamiento mayor. Además de eso, fue posible identificar diferencias entre niños y niñas cuanto a los patrones proxémicos de involucramiento visual en la interacción. Los resultados de este estudio señalizan nuevos sentidos para el análisis de la interacción profesor-alumno con enfoque en aspectos no verbales en la construcción de las relaciones de enseñanza y aprendizaje.

Palabras clave: interacción profesor-estudiante; proxémica; comunicación no verbal

\footnotetext{
${ }^{1}$ Universidad Finis Terrae, Faculty of Education, Psychology and Education, Santiago, Chile; dfarsani@uft.cl

2 Universidade Estadual de Campinas - Campinas - SP - Brasil; jamendes@unicamp.br
} 


\section{INTRODUÇÃO}

As interações em sala de aula são importantes fenômenos sociais. Os modos pelos quais um professor interage com seus alunos são fundamentais para a construção de um processo comunicativo que estabeleça vínculos e melhores possibilidades de compreensão sobre a interação em sala de aula (Rosa \& Farsani, 2021). Esse tipo de construção da interação representa elementos importantes dos padrões das relações sociais, os quais, muitas vezes, não são considerados como tendo um papel importante nos processos educacionais. Das pesquisas que têm focalizado a interação em sala de aula, em geral, a captura desses processos ocorre pelo posicionamento de uma camera em um tripé colocado no fundo de uma sala de aula (Erickson, 1973; Condon, 1982; McNeill, 1992). Podemos dizer que os dados capturados por essa câmera sempre representariam a perspectiva de uma terceira pessoa sobre as interações entre professor e os alunos e entre os pares. Nesses casos, o ponto de vista da câmera poderia ser entendido como sendo uma perspectiva externa. Essa perspectiva, de terceira pessoa, significaria que os registros da interação não estão sendo feitos a partir das perspectivas do professor e dos alunos. Neste estudo, propomos incorporar uma primeira pessoa na realização da filmagem da interação em sala de aula. Para que seja possível essa perspectiva de primeira pessoa, as gravações interativas de vídeo foram feitas a partir de minicâmeras de vídeo montadas em óculos usados pelos estudantes. Os óculos são dispositivos tecnológicos que vêm sendo usados, mais recentemente, nas pesquisas educacionais. Esse tipo de tecnologia visual pode fornecer novas oportunidades para registrar padrões sutis, mas importantes, nas salas de aula (Sharma, Jermann, \& Dillenbourg, 2015).

Esses óculos permitem que os pesquisadores gravem e revisem eventos que o aluno observa, o que torna possível perceber o seu ponto de vista, fazendo com que a visão sobre a interação ocorra a partir de um participante dela. Esse visual pode apresentar diversos elementos relacionados à atenção visual do aluno, seja o que está escrito no quadro-negro ou no material que o aluno dispõe em sua carteira, ou então, perceber gestos e elementos visuais que compõem a comunicação não verbal. Também a partir desse recurso de registro é possível identificar o quanto da atenção visual dos alunos é dispensada ao professor e a outros alunos da sala.

Neste estudo apresentaremos resultados sobre a atenção visual de estudantes na sala de aula de uma professora, com 38 anos e 10 anos de experiência docente em uma escola pública da cidade de Santiago, no Chile. Analisando os dados obtidos pelas minicâmeras de vídeo montadas nos óculos usados pelos estudantes, encontramos dois padrões diferentes de interação no caso dessa professora. Um primeiro, em que há momentos no mês em que ela não interage muito com os alunos, sempre mantendo uma distância e um segundo padrão de interação em que há momentos, nesse mesmo mês, nos quais ela interage muito mais com os alunos, em níveis maiores de proximidade.

Neste artigo, pretendemos discutir esses padrões interacionais de sala de aula, que foram identificados a partir das perspectivas dos alunos por meio de vídeos gerados pelas câmeras montadas em seus óculos. A atenção visual dos alunos é um dos aspectos mais importantes da interação não verbal em sala de aula e desempenha um papel extremamente significativo no engajamento interacional e na aprendizagem (Farsani, Breda, \& Sala, 2020; Farsani, Radmehr, Alizadeh, \& Zakariya, 2021). Tomaremos a noção de proxêmica para medir o comportamento interacional em sala de aula entre os alunos e a professora. A noção de proxêmica neste estudo está relacionada ao estudo silencioso da comunicação, frequentemente referida para tratar como "as pessoas se regulam no espaço e como elas se movem no espaço" (Collier, 1995, p. 235). Pretendemos explorar de que modo as mudanças sutis no comportamento proxêmico da professora alteram a dinâmica da interação em sala de aula e a atenção visual do aluno.

\section{Proxêmica: a comunicação a partir do uso do espaço}

A noção de proxêmica pode ser entendida como uma parte da linguagem não-verbal (ou linguagem corporal). Há vários estudos nesse campo que abordam de que modo pequenas mudanças em nossa linguagem corporal podem ter efeitos significativos na interação social. Por exemplo, uma postura corporal mais aberta e expansiva, como por exemplo, ficar em pé e apresentar muito espaço entre os pés, com as mãos nos quadris, levam a mudanças na percepção e no comportamento interacional, de acordo com o estudo desenvolvido por Carney, Cuddy e Yap (2015). Nesse estudo, os autores discutem de que modo esse tipo de comportamento não-verbal é, frequentemente, associado a uma maior probabilidade de contratação em uma entrevista de emprego simulada (Cuddy, Wilmuth, Yap, \& Carney, 2015). Esse mesmo comportamento corporal pode elevar as experiências relacionadas a emoções positivas e diminuir as experiências de emoções negativas, como discutido por Veenstra, Schneider e Koole (2017). Um outro exemplo, algo tão básico como uma "postura ereta" pode ter efeitos positivos nas realizações acadêmicas das crianças. Nesse sentido, no Japão, o estudo desenvolvido por Inagaki, Shimizu e Sakairi (2018) identificou efeitos positivos na produtividade da escrita acadêmica, assim como melhores pontuações em um teste de cálculo, quando os estudantes adotavam uma postura ereta. Em outro estudo desenvolvido no Reino Unido, Farsani (2015) explorou de que modo a orientação corporal e o ângulo de virada do professor em relação 
aos interlocutores apresentam um papel importante no processo de engajamento dos estudantes durante as aulas de matemática.

Esse conceito de proxêmica, cunhado pelo antropólogo americano Edward T. Hall (1959), atraiu muitos antropólogos, psicólogos e educadores contemporâneos. Hall propôs em seus estudos uma análise da proxêmica da comunicação interpessoal em diferentes contextos culturais. Para isso, ele propôs quatro categorias para tratar do uso de espaço pelas pessoas nas interações, focalizando a distância que elas mantêm com os outros interactantes: espaço íntimo (até $45 \mathrm{~cm}$ ), espaço pessoal (até $120 \mathrm{~cm})$, espaço social (até $370 \mathrm{~cm})$ e espaço público (mais de $370 \mathrm{~cm}$ ). Neste artigo, ao tratarmos das interações em sala de aula, faremos uso das quatro categorias referents ao uso do espaço: Privado, Pessoal, Profissional e Público. Além disso, gostaríamos de examinar qual desses quatro espaços tem maior efeito sobre a atenção visual dos alunos.

Hall (1959), além de discutir sobre como "o espaço fala" nas interações sociais, também obervou que pessoas de diferentes culturas usam o espaço de maneiras diferentes em seus encontros de comunicação social. Do mesmo modo em que a linguagem verbal varia em cada contexto cultural, o mesmo acontece com o uso do espaço entre as díades sociais. Por exemplo, um dos autores deste artigo viveu em três países muito diferentes, cada um deles em um continente diferente (Irã, Reino Unido e Chile), os quais apresentam normas interativas socioculturais diametralmente opostas. Ele percebeu imediatamente que os ingleses, iranianos e chilenos têm sistemas de proxêmica fundamentalmente diferentes em seus encontros sociais e comunicativos.

O que é considerado uma distância pessoal socialmente aceitável entre as díades sociais no Reino Unido pode ser considerada rude ou mesmo ofensivo no Chile. Na Inglaterra, é socialmente aceitável ficar a uma distância de $90 \mathrm{~cm}$ dos outros interlocutores. No Irã, essa distância é um pouco menor (Mehrabian, 1972), enquanto no Chile os interlocutores se aproximam ainda mais durante a comunicação interpessoal. Na Inglaterra, a proximidade entre os interlocutores pode levar os indivíduos a mostrar sinais de desconforto, desde um gesto muito clássico de cruzar os braços até o uso da expressão verbal "tire sua cara da minha". É possível afirmar que as normas socioculturais do comportamento proxêmico varia consideravelmente no Irã e no Chile, quando comparado ao Reino Unido. No Irã, à medida que o espaço interpessoal entre as díades sociais aumenta, isso pode resultar em que sejam ditas frases, pelos iranianos, que expressam um desconforto como, por exemplo, "não sinto o cheiro" ou "não posso sentir o seu cheiro". Isso significa simplesmente "não sinto o cheiro e nem você, então vamos nos aproximar".

No Chile, devido às normas socioculturais, o espaço pessoal é ainda mais próximo do que no Irã. No Chile, estar à distância entre as díades sociais é socialmente grosseiro e é considerada uma má prática. Em tais circunstâncias, os chilenos se tornam mais conscientes e mostram seu desconforto através da expressão "No muerdo!", que se traduz como "Eu não mordo". Essa frase provavelmente reflete a proximidade que os interlocutores chilenos esperariam um do outro nas interações sociais. É interessante notar que a noção de proxêmica varia não apenas entre culturas, mas também entre indivíduos e situações. Por exemplo, pessoas em todo o mundo tendem a manter uma proximidade maior em metrôs ou em elevadores. Além disso, os interlocutores tendem a se aproximar mais do que o normal em ambientes barulhentos.

A noção de proxêmica pode suscitar questões importantes para pensar as interações professor/aluno, ao focalizarmos como os usos do espaço visual e os posicionamentos corporais dos participantes assumem um papel nessas interações em que se estabelecem relações de aprendizagem. A proxêmica é, frequentemente, vista como um recurso que os professores podem utilizar rotineiramente, não apenas para regular um processo de tomada de turnos na interação de forma mais tranquila, mas também com o intuito de observar de que modo os comportamentos não verbais e inconscientes do professor podem promover certos padrões interativos em sala de aula (Roger, 2015).

Outros pesquisadores examinaram os efeitos do uso de diferentes línguas faladas por alunos bilíngues em suas mudanças de proxêmica e comportamentos não-verbais (Collier 1983, Farsani, 2015; 2016). Por exemplo, Collier (1983) realizou um estudo proxêmico apontando que a distância interpessoal é um fator significativo na interação em sala de aula, de acordo com os padrões culturais interativos envolvidos. Em sua análise, feita a partir de uma gravação de vídeo detalhada de uma sala de aula chinesa-americana, Collier mostrou que a língua de instrução determinava padrões particulares de proxêmicas e espaços interpessoais. A língua cantonêsa falada pelos estudantes, quando usada como meio de instrução, não apenas provocou um espaço proxêmico mais próximo entre os interlocutors como também possibilitou, de forma significativa, mais ângulos de virada (orientação corporal) entre os alunos e professor. Essa situação possibilitou uma atmosfera mais envolvente $e$ aumentou a atenção dos alunos. Além disso, os alunos ficaram mais propensos a se comunicar sobre tópicos relacionados à tarefa desenvolvida.

O estudo desenvolvido por Farsani (2015), sobre o comportamento proxêmico entre estudantes de ascendência persa no Reino Unido, focalizou as mensagens matemáticas multimodais trocadas entre estudantes britânico-iranianos na interação. Além disso, o autor examinou as maneiras pelas quais diferentes idiomas 
(inglês e farsi) afetavam a orientação corporal dos alunos e o comportamento proxêmico na interação na sala de aula. $O$ inglês era frequentemente empregado para manter as tarefas técnicas escolares em movimento, enquanto o farsi era usado para fazer piadas, gerenciamento de comportamentos e envolvimento emocional, portanto o farsi era usado como um gatilho verbal que produzia um ângulo de maior aproximação e atenção corporal entre os alunos. Nesse sentido, é possível pensar de que modo as proxêmicas variam de acordo com os diferentes papéis da linguagem e das línguas em uso na interação social. A proxêmica também pode ser observada em relação às diferenças culturais e de gênero dentro da sociedade. Assim sendo, o Autor 1 observou que as meninas mantinham mais proximidade no direcionamento do corpo (o ângulo de virada) voltado para o outro, enquanto discutiam ideias e desenvolviam tarefas. Por outro lado, os meninos mantinham uma distância corporal maior, com um ângulo de virada menor e menos contato visual entre si.

Diversos estudos anteriores sobre a linguagem e a interação em sala têm mostrado os diferentes efeitos que a linguagem verbal pode ter na construção das relações de aprendizagem (Barreira \& Maluf, 2004; Bernardes, 2011; Kripka, Quadros, Oliveira, \& Ramos, 2017). Entendemos que os estudos sobre a interação em sala de aula com foco em elementos não verbais que compõem essas interações, em particular os estudos sobre a comunicação proxêmica, podem trazer aspectos relevantes para pensar os processos de aprendizagem em sala de aula. Além disso, torna-se interessante investigar de que forma questões de gênero e outras possíveis categorias de espaço, relativos a diferenças culturais em sala de aula, podem afetar a atenção visual de alunos em diferentes temas abordados.

\section{MÉTODO}

O levantamento de dados deste estudo foi feito a partir de registros em uma sala de aula, em três dias diferentes (28.07.2017; 28.08.2017; e 11.08.2017), em uma escola dos anos iniciais na cidade de Santiago, Chile. Cada momento de registro consistiu em duas aulas consecutivas de 45 minutos ( 90 minutos por dia). Nesses encontros, a professora da sala de aula e uma amostra de 18 alunos selecionados aleatoriamente ( 6 alunos por dia) foram convidados a usar uma minicâmera de video, montada em armações de óculos.

Os dados discutidos neste artigo fazem parte de uma pesquisa maior que tem por finalidade investigar os padrões de comportamento interacional pela professora da sala de aula e pelos alunos. Nosso foco é capturar e analisar os padrões de olhar entre os alunos e a professora em sala de aula, com a finalidade de promover um locus de observação sobre as práticas interativas em sala de aula a partir da perspectiva de uma primeira pessoa participante da interação (Prieto, Sharma, \& Dillenbourg, 2015). A ideia de usar o olhar como um meio para analisar como se constroem as relações de ensino e aprendizagem é de particular interesse para muitos pesquisadores. Em nosso trabalho desenvolvido anteriormente, prestamos atenção especial à importância do ponto de vista de primeira pessoa, algo que, tradicionalmente nas pesquisas sobre interação não têm sido realizadas; em geral, nesses estudos o posicionamento da câmera sempre parte de um terceiro olhar, seja um ponto fixo na sala, ou o olho de um pesquisador que opera a câmera.

Ao montar as câmeras nos óculos dos alunos, conseguimos calcular e obter uma melhor perspectiva da classe, a partir da visão do estudante. A idade média dos estudantes participantes era em torno de 6 a 7 anos. Foram selecionados aleatoriamente 12 meninos e 6 meninas. No total, obtivemos quase 27 horas de gravações interacionais realizadas a partir da ótica dos alunos. Essas câmeras de vídeo tinham uma qualidade de gravação de trinta quadros por segundo (30 fps), para cada vídeo. Foi realizada uma amostragem de cada frame dentro de cada segundo, de forma a detectar a presença de faces na imagem. Montar uma minicâmera de vídeo não representou ser uma grande mudança, nem uma grande perturbação para os alunos, apenas incicialmente, entretanto, depois de um tempo transcorrido, a câmera nos óculos passou a ser um objeto facilmente incorporado. Em nossa experiência, após alguns minutos, os alunos esquecem completamente que estão usando os óculos.

\section{Processamento visual automatizado para a análise quantitativa da proxêmica em sala de aula}

A incorporação da tecnologia visual para observar a interação pode oferecer novas oportunidades para observar padrões sutis mas importantes nas práticas interativas em sala de aula. Para a análise desses padrões, a partir dessa produção visual, é possível incorporar aspectos quantitativos pela medição e análise dos usos do espaço. Nos aspectos qualitativos, é possível pensar na continuidade do estudo pela busca de produção de sentidos pelos participantes para esses padrões da interação em questão.

Neste artigo, pretendemos apresentar uma análise quantitativa a partir de uma abordagem metodológica automatizada e objetiva para analisar os quadros produzidos nos dados visuais. Para todos os quadros amostrados fizemos o uso do recurso do Google Images para a identificação da presença de faces. Inserimos fotos da professora da sala de aula e esse recurso identificou, de modo automático e objetivo, todos os quadros em que uma imagem da professora apareceu em cada quadro capturado pelos alunos. Foram analisados um total de 97200 quadros. Nosso interesse 
estava, principalmente, nos casos em que os alunos mantinham sua atenção visual na professora. Houve momentos em que mais de duas faces estavam presentes no mesmo quadro, por exemplo, quando aparecia a professora e um outro estudante que acabara de chegar à aula. Nesses casos, decidimos descartar o quadro, pois a atenção visual do aluno poderia ter sido fixada no outro aluno que estava ao lado da professora e não nela. Houve outros momentos em que descartamos deliberadamente quadros que não foram contabilizados na análise quantitativa, isso incluía aqueles em que a nitidez dos quadros era baixa ou desfocada e, portanto, não era possível discernir se a professora estava, ou não, olhando para o aluno.

Depois que o recurso de identificação de imagem detectava a face da professora em um quadro (capturado pelos óculos dos alunos), esse quadro recebia um número de identificação exclusivo e, também, era examinado individualmente para observar algumas variáveis não verbais. Por exemplo, se a professora estava olhando diretamente para os alunos, se estava gesticulando, apontando, andando, sentando-se (veja a Figura 1) e, finalmente, sua distância proxêmica em relação ao aluno que registrou a imagem a partir seus óculos. Esse processo foi organizado em uma planilha no Excel, com dupla entrada 0 ou 1 (indicando 'se não aconteceu' (0) ou 'se aconteceu' (1)) e, em seguida, foram realizadas análises estatísticas para medir essas ocorrências.

A Figura 1 ilustra um conjunto de variáveis, por exemplo, p1, p2, p3 e p4, em que p1 é quando a professora aparece no Espaço privado de um aluno, p2 no Espaço pessoal, p3 no Espaço profissional e p4 no Espaço público do aluno. Também consideramos outras variáveis, tais como se a professora tem contato visual direto com os alunos, se o corpo da professora está voltado na direção dos estudantes ou para longe deles, se a professora em sala de aula está caminhando ou permanece estática em sua posição na classe.

\section{DISCUSSÃO: MEDINDO A PRÔXEMICA NA INTERAÇÃO PROFESSORA-ESTUDANTES}

Para a análise, consideramos a proxêmica como parte integrante da interação professora-estudantes. Para isso, nosso foco esteve em observar como cada estudante e a professora estavam posicionados um em relação ao outro, momento a momento. $\mathrm{Na}$ análise das proxêmicas, medimos a que distância a professora estava de pé, ou sentada, em relação ao estudante-observador em questão. Também registramos a que distância em que cada estudantes estava sentado na sala de aula, para isso foi feita uma medida física da distância entre as mesas nos planos laterais e sagitais (da esquerda para a direita e da frente para trás, respectivamente). Como resultado, observamos que as mesas estavam a um metro de distância (da esquerda para a direita), com $90 \mathrm{~cm}$ entre cada fila (da frente para trás). Sentados em suas mesas, cada aluno utilizava aproximadamente 110 $\mathrm{cm}$ de espaço no total (da frente para trás). Portanto, se o estudante-observador estivesse sentado na segunda fila, na mesma coluna em que a professora se encontrava, a distância entre o observador e a professora seria em torno de aproximadamente $220 \mathrm{~cm}$.

A regra de Pitágoras foi usada para identificar a distância entre o estudante-observador e a professora se a professora estivesse em pé (ou sentada) em uma coluna diferente de onde esse observador estivesse sentado. Ao obter uma estimativa aproximada de quão distante o observador estava da professora, classificamos cada quadro em termos das proxêmicas: espaço privado, pessoal, profissional e público.

Para o estudo das proxêmicas na interação em sala

Figura 1. Exame de Variáveis não Verbais.

\begin{tabular}{|c|c|c|c|c|c|c|c|c|c|c|c|c|c|c|c|}
\hline \multicolumn{2}{|c|}{01} & \multirow{2}{*}{ B } & \multirow[t]{2}{*}{$\vdots$} & \multirow{2}{*}{\multicolumn{2}{|c|}{$\begin{array}{c}\times \vee f_{x} \\
C\end{array}$}} & \multicolumn{10}{|l|}{ base line } \\
\hline 4. & & & & & & D & E & $\mathrm{F}$ & G & $\mathrm{H}$ & I & J & K & L & $M$ \\
\hline 1 & $10 \mathrm{~s}$ & & & P1 & & P2 & P3 & P4 & Orient.corpo & olhar & gestual & pernas aber. & caminhando & sob oculos & apontando \\
\hline 2 & & & 1 & & 0 & 0 & 1 & 0 & 1 & 1 & 0 & 0 & 0 & 0 & 0 \\
\hline 3 & & & 1 & & 0 & 0 & 1 & 0 & 1 & 1 & 0 & 0 & 0 & 0 & 0 \\
\hline 4 & & & 1 & & 0 & 0 & 1 & 0 & 0 & 0 & 0 & 0 & 0 & 0 & 0 \\
\hline 5 & & & 1 & & 0 & 0 & 1 & 0 & 0 & 0 & 0 & 0 & 0 & 0 & 0 \\
\hline 6 & & & 1 & & 0 & 0 & 1 & 0 & 1 & 0 & 1 & 0 & 0 & 0 & 0 \\
\hline 7 & & & 1 & & 0 & 0 & 1 & 0 & 1 & 0 & 0 & 0 & 0 & 0 & 0 \\
\hline 8 & & & 1 & & 0 & 0 & 1 & 0 & 1 & 0 & 0 & 0 & 0 & 0 & 0 \\
\hline 9 & & & 1 & & 0 & 0 & 1 & 0 & 1 & 0 & 1 & 0 & 0 & 0 & 0 \\
\hline 10 & & & 1 & & 0 & 0 & 1 & 0 & 0 & 0 & 0 & 0 & 0 & 0 & 0 \\
\hline 11 & & & 1 & & 0 & 0 & 1 & 0 & 0 & 0 & 0 & 0 & 0 & 0 & 0 \\
\hline 12 & & & 2 & & 0 & 0 & 0 & 1 & 0 & 0 & 0 & 0 & 0 & 0 & 0 \\
\hline 13 & & & 2 & & 0 & 0 & 0 & 1 & 0 & 0 & 0 & 0 & 0 & 0 & 0 \\
\hline 14 & & & 2 & & 0 & 0 & 0 & 1 & 0 & 0 & 0 & 0 & 0 & 0 & 0 \\
\hline 15 & & & 2 & & 0 & 0 & 1 & 0 & 0 & 1 & 0 & 0 & 0 & 0 & 0 \\
\hline 16 & & & 2 & & 0 & 0 & 1 & 0 & 0 & 0 & 1 & 0 & 0 & 0 & 0 \\
\hline 17 & & & 2 & & 0 & 0 & 1 & 0 & 0 & 0 & 1 & 0 & 0 & 0 & 0 \\
\hline in & , & & Hoj & & $\oplus^{n}$ & n & a & n & & & $1:$ & n & - & n. & \\
\hline
\end{tabular}


de aula, realizamos uma análise quantitativa com base nos dados numéricos obtidos, organizados em uma planilha no Excel, a partir da quantificação de variáveis não-verbais. Foi usada uma análise de variância, a partir do recurso two-way ANOVA, com dupla entrada: a data da aula e o sexo dos estudantes como os dois principais fatores. O nível de significância foi definido como 0,05 e o ajuste de Bonferroni foi aplicado aos valores de $p$. Apresentamos quatro gráficos diferentes, sendo cada gráfico a representação do padrão proxêmico da professora em relação a sua distância dos estudantes. Além disso, consideramos o sexo dos estudantes como um outro fator, com a finalidade de observar se há diferenças de preferências proxêmicas relativas às meninas e aos meninos. Também observar se esses posicionamentos podem ajudá-los a prestar mais atenção visual na professora e a se envolver na aula. Dessa maneira, é interessante pensar como as relações de gênero podem suscitar questões sobre proxêmicas na interação em sala de aula.

\section{Proxêmica: aproximação e distanciamento entre professora e estudantes \\ O caso do espaço privado}

O espaço privado é identificado quando a distância da professora em sala de aula em relação ao estudante é de $0 \mathrm{~cm}$ (quando há toque) a $45 \mathrm{~cm}$. Parece que nessa data específica (28.07.2017), houve um efeito significativo no número médio de quadros em que os alunos olharam para a professora, a uma distância de proximidade $1\left(F_{2,15}=4.97, p=0.027\right)$. Os testes post-hoc mostraram uma diferença significativa entre a classe 1 $(28-07)$ e a classe $2(11-08)(p=0,04)$. As diferenças de efeito entre os sexos no número médio de quadros não foram significativas $\left(F_{1,16}=4.13, p=0.065\right)$.

Figura 2. Interação no Espaço Privado.

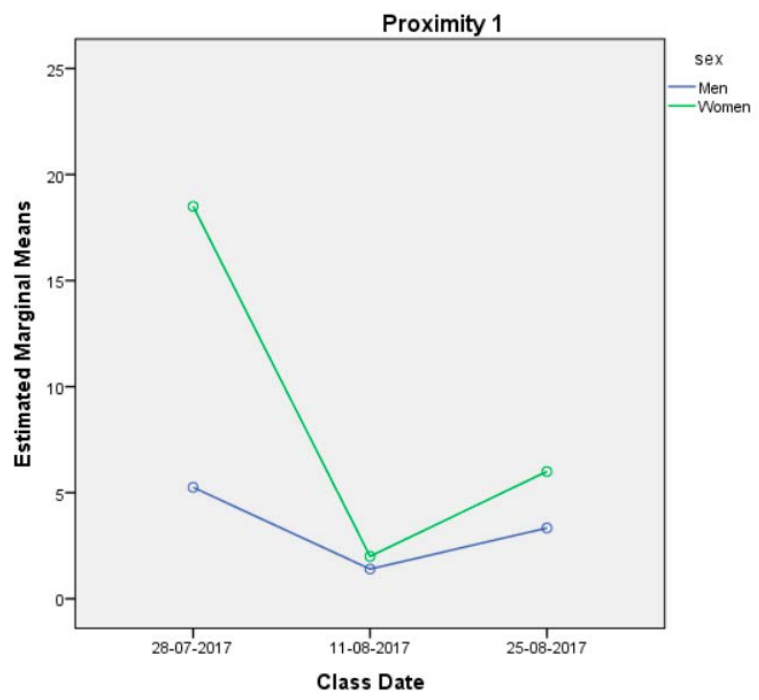

\section{O caso do espaço pessoal}

O espaço pessoal é identificado quando a distância da professora em sala de aula em relação ao aluno é de 46 a $120 \mathrm{~cm}$. Para p2, houve um aspecto principal significativo em relação à data da aula $\left(F_{2,15}=3.77, p=\right.$ $0.055)$ e o aspecto sexo não foi significativo $\left(F_{1,16}=2.00\right.$, $p=0.186$ ). No entanto, houve uma interação significativa entre a data da aula e o sexo dos estudantes $\left(F_{5,12}\right.$ $=3.21, p=0.045)$, indicando que a data da aula em que ocorreu a aula afetou significativamente a diferença entre meninos e meninas na primeira e na terceira classe $\left(\mathrm{t}_{12}=-2.59, \mathrm{p}=0.024\right)$.

\section{O caso da distância profissional}

O espaço profissional ocorre quando a distância da professora em sala de aula em relação ao aluno é de $121 \mathrm{a} 360 \mathrm{~cm}$. Para a distância profissional, não houve efeito principal significativo da data da aula $\left(F_{2,15}=0.27\right.$, $p=0.772)$ nem do sexo do estudante $\left(F_{1,16}=3.04, p=\right.$ $0.107)$. A interação entre a data da aula e o sexo também não foi significativa $\left(F_{5,12}=1.5, p=0.263\right)$.

\section{0 caso do espaço público}

O espaço público indica que a distância da professora em sala de aula em relação ao aluno é superior a $360 \mathrm{~cm}$. Para o espaço público, não houve um aspecto principal significativo da data da aula $\left(F_{2,15}=0.886, p=0.438\right)$ nem do sexo $\left(F_{1,16}=0.175, p=0.683\right)$. A interação entre a data da aula e o sexo também não foi significativa $\left(F_{5}\right.$, ${ }_{12}=1.865, \mathrm{p}=0.175$ ).

Esses resultados, tomados em conjunto, sugerem que há momentos no decorrer do mês em que há uma diferenciação no comportamento interacional da professora em relação aos espaços proxêmicos: espaços privados e pessoais (na data de 28.07.2017). No entanto, duas semanas depois (11.08.2017), esse padrão

Figura 3. Interação no Espaço Pessoal.

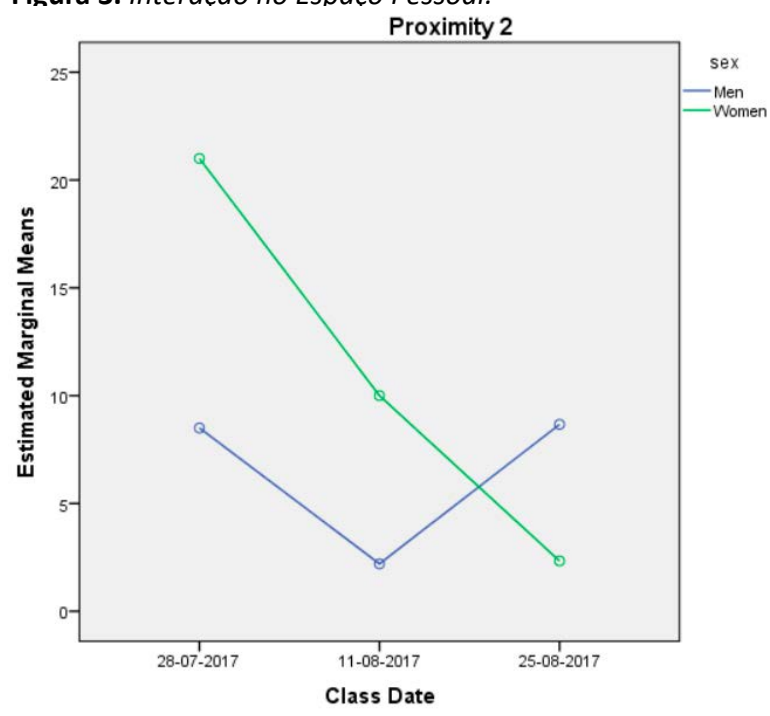


proxêmico de comportamento interacional cai e, deixa de haver a aproximação dos alunos. Posteriormente, duas semanas depois (25.08.2017), parece haver um aumento na proximidade interacional da sala de aula. Isso significa que há momentos no mês em que a professora da sala de aula está mais envolvida física e não verbalmente, utilizando todo o espaço disponível à sua disposição em sua prática profissional de ensino. Além disso, é interessante notar que, dessa amostra muito pequena que temos, que as meninas eram visualmente mais engajadas e prestavam mais atenção visual à professora, principalmente quando a professora mantinha o espaço pessoal com essas estudantes. De outro lado, isso não foi significativo em relação aos outros tipos de espaço e, no caso da interação com os meninos, também não houve essa significância.

Figura 4. Interação no Espaço Profissional.

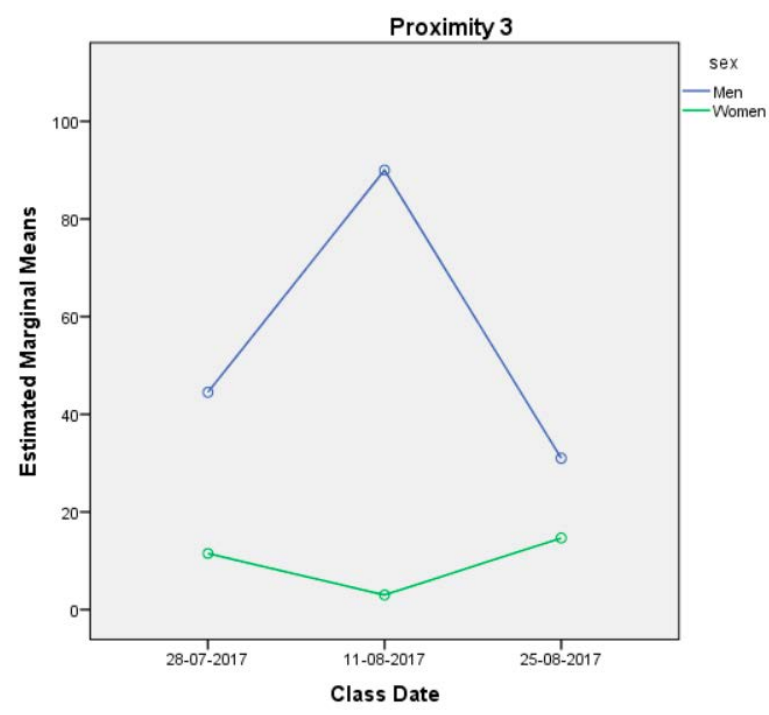

Figura 5. Interação no Espaço Público.

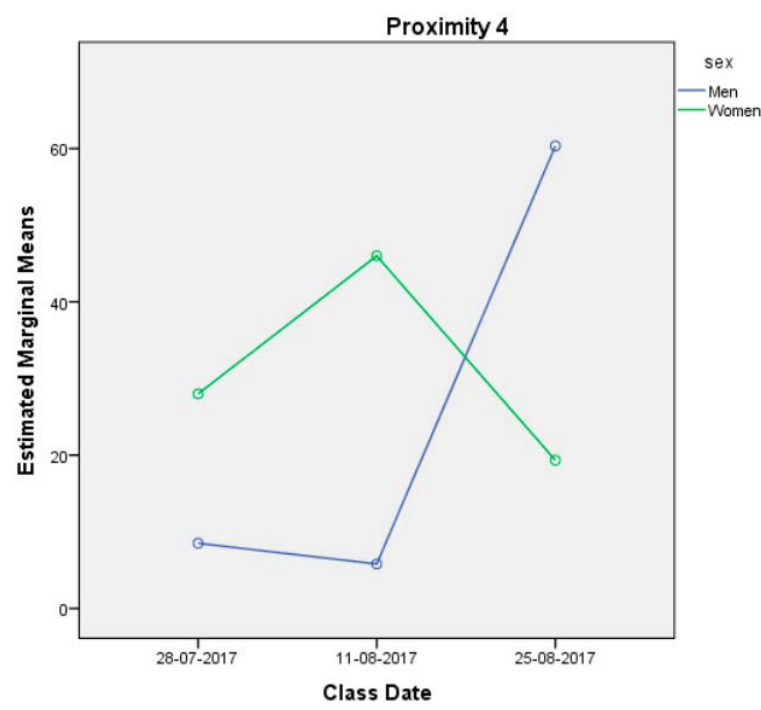

É possivel identificar, desse modo, um movimento nos comportamentos proxêmicos da professora em relação aos estudantes, os quais sofrem variações ao longo do mês em que foram registradas as aulas: com momentos de maior proximidade (de 0 a $120 \mathrm{~cm}$ ) e de distanciamento. Houve momentos em que a professora não interagia tanto, mantendo-se fisicamente mais distante dos alunos (mais de 3,6 metros) e, em muitos desses momentos, usava a mesa como uma barreira entre ela e os alunos.

Além disso, foi possível identificar diferenças nas preferências dos padrões proxêmicos quando levada em conta a questão de gênero. Os meninos e as meninas mostraram preferir padrões proxêmicos específicos para se envolver visualmente, principalmente no espaço pessoal.

\section{CONSIDERAÇÕES FINAIS}

Este artigo apresentou um estudo realizado nos anos iniciais em uma escola pública no Chile, onde uma amostra de 18 estudantes, selecionados aleatoriamente, usavam uma minicâmera de vídeo montada em óculos. Nossos resultados mostram que houve momentos, no espaço de um mês, em que a professora da sala de aula interagiu com os alunos em um nível proxêmico mais próximo (de 0 a $120 \mathrm{~cm}$ ). Também identificamos que houve momentos, nesse mesmo período, em que a professora não interagia tanto, ela estava fisicamente mais distante dos alunos (mais de 3,6 metros) e, também, usava a mesa como uma barreira entre ela e os alunos. Além disso, meninos e meninas apresentaram preferências de padrões proxêmicos específicos para se envolver visualmente, principalmente no espaço pessoal.

Podemos afirmar que até o momento ainda são poucas as ferramentas metodológicas desenvolvidas para medir objetiva e automaticamente a atenção visual, na esperança de medir e avaliar o envolvimento visual em relação às proxêmicas em sala de aula. Ainda se fazem necessários estudos que examinem de que modo as mudanças não-verbais sutis e as proxêmicas podem ter uma maior probabilidade de afetar diretamente a atenção visual dos estudantes, levantando em consideração as questões de gênero. Gostaríamos ainda de expandir e examinar em que lugar do espaço físico da sala de aula e em que distância (a relação proxêmica entre professor e alunos) há alunos que, provavelmente, estão visualmente mais ou menos envolvidos com o professor.

Esses resultados indicam a relevância do desenvolvimento de estudos futuros que busquem articular a questão das proxêmicas em sala de aula, a partir das categorias de espaço apontadas, com as práticas discursivas que são verbalmente trocadas dentro de cada um dos quatro espaços diferentes. Além disso, como continuidade desse estudo, podem ser elencadas questões que conduzam a uma análise qualitativa. Questões 
essas que discutam a interação em sala de aula a partir dos sentidos produzidos pelos participantes da interação para esses tipos de organização do uso do espaço. Para isso é interessante destacar o desenvolvimento de uma análise que leve em conta aspectos particulares e específicos, referentes aos sentidos culturais que os participantes trazem para a interação, com foco nos usos do espaço, ou seja, discutir de que forma são produzidos sentidos pelos participantes para as proxêmicas levantadas em sala de aula.

Para além disso, é importante ressaltar que os estudos da interação em sala de aula podem trazer aspectos para discutir as formas, os estilos e a qualidade das mensagens que são transmitidas verbal e não verbalmente, as quais podem contribuir na prática profissional dos professores. Acreditamos que otimizações dessas mensagens não-verbais, na maioria das vezes muito sutis e silenciosas, podem ter um efeito positivo direto, não apenas entre os estudantes que se envolvem visualmente, mas também na construção das relações de ensino e aprendizagem que se estabelecem em sala de aula. Uma recomendação para pensar a formação de professores é incorporar nas discussões, promovidas nesses processos formativos, as funções comunicativas da linguagem não-verbal em sala de aula.

\section{REFERÊNCIAS}

Barreira, S. D.; Maluf, M. R. (2004). Variação lingüística e alfabetização: um estudo com crianças da primeira série do ensino fundamental. Psicologia Escolar e Educacional, 8(1), 35-46.

Bernardes, M. E. M. (2011). Atividade educativa, pensamento e linguagem: contribuições da psicologia histórico-cultural. Psicologia Escolar e Educacional, 15(2), 323-332.

Carney, D. R.; Cuddy, A. J. C.; Yap, A. J. (2015). Review and summary of research on the embodied effects of expansive (vs. contractive) nonverbal displays. Psychological Science, 26(5), 657-663. https://doi. org/10.1177/0956797614566855

Collier, J. (1995). Photography and visual anthropology. In: P. Hockings (Ed.), Principles of Visual Anthropology (2 ${ }^{\mathrm{a}}$ ed., pp. 235-254). The Hague: Mouton.

Collier, M. (1983). Nonverbal Factors in the Education of Chinese American Children: A Film Study. San Francisco: Asian American Studies. San Francisco State University.

Condon, W. S. (1982). Cultural microrhythms. In: Davis, M. (Ed.), Interaction rhythms: Periodicity in communicative behavior (pp. 53- 76). New York, Human Science Press.

Cuddy, A. J.; Wilmuth, C. A.; Yap, A. J.; Carney, D. R. (2015). Preparatory power posing affects nonverbal presence and job interview performance. Journal of Applied Psychology, 100(4), 1286-1295. https://doi.org/10.1037/a0038543
Hall, E. T. (1959). The Silent Language. Greenwich: Fawcett Publications.

Erickson, F. (1973). What makes a good ethnography "ethnographic"?. Council on Anthropology and Education Newsletter, 4(2), 10-19.

Farsani, D. (2015). Making multi-modal mathematical meaning in multilingual classrooms (Tese de doutorado). University of Birmingham, Reino Unido. Recuperado de https://core. ac.uk/download/33528004.pdf

Farsani, D. (2016). Complementary functions of learning mathematics in complementary schools. In: P. C. Clarkson; A. Halai (Eds.), Teaching \& Learning Mathematics in Multilingual Classrooms: Issues for policy, practice and teacher education (pp. 227-247). Rotterdam: Sense Publishers.

Farsani, D.; Breda, A.; Sala, G. (2020). ¿Cómo los gestos de los maestros afectan a la atención visual de las estudiantes durante el discurso matemático? REDIMAT - Journal of Research in Mathematics Education, 9(3), 220-242. https:// doi.org/10.17583/redimat.2020.5185

Farsani, D.; Radmehr, F.; Alizadeh, M.; Zakariya, Y. F. (2021). Unpacking the black-box of students' visual attention in mathematics and English classrooms: Empirical evidence using mini-video recording gadgets. Journal of Computer Assisted Learning. 37(3), 773-781. doi.org/10.1111/ jcal.12522

Inagaki, K.; Shimizu, T.; Sakairi, Y. (2018). Effects of posture regulation on mood states, heart rate and test performance in children. Educational Psychology, 38(9), 1129-1146.

McNeill, D. (1992). Hand and mind: What gestures reveal about thought. Chicago: The University of Chicago Press.

Mehrabian, A. (1972). Nonverbal communication. Chicago: Aldine-Atherton.

Kripka, M. L.; Quadros E. L. L.; Oliveira, R. A. P.; Ramos, M. G. (2017). Educação em ciências e matemática: A função da linguagem no contexto da sala de aula. EnsaioPesquisa em Educação em Ciências, 19, 1-18. https://doi. org/10.1590/1983-21172017190133

Prieto, L. P.; Sharma, K.; Dillenbourg, P. (2015). Studying teacher orchestration load in technology-enhanced classrooms. In: Design for Teaching and Learning in a Networked World (pp. 268-281). Toledo, ES: Springer International Publishing.

Rogers, B. (2015). Classroom behaviour: a practical guide to effective teaching, behaviour management and colleague support. London, UK: SAGE Publications.

Rosa, M.; Farsani, D. (2021). Two fish moving in their seas: How does the body language of teachers show itself who teach mathematical equations? Acta Scientiae. 23(4), 141-168.

Sharma, K.; Jermann, P.; Dillenbourg, P. (2015). Displaying Teacher's Gaze in a MOOC: Effects on Students' Video Navigation Patterns. In: Design for Teaching and Learning 
in a Networked World (pp. 325-338). Toledo, ES: Springer International Publishing.

Veenstra, L.; Schneider, I. K.; Koole, S. L. (2017). Embodied mood regulation: the impact of body posture on mood recovery, negative thoughts, and mood-congruent recall. Cognition and Emotion, 31(7), 1361-1376.

Agradecimentos

Gostaríamos de agradecer o apoio financeiro ao projeto pela Agência Nacional Chilena para Pesquisa e Desenvolvimento, ANID/PAI 77200008.

Recebido: 10 de outubro de 2019 Aprovado: 11 de abril de 2020 